\title{
An observational and modelling analysis of Laptev Sea (Arctic Ocean) ice variations during summer
}

\author{
K. Görgen, ${ }^{1}$ J. Bareiss, ${ }^{1}$ A. Helbig, ${ }^{1}$ A. Rinke, ${ }^{2}$ K. Dethloff ${ }^{2}$ \\ ${ }^{1}$ Department of Climatology, Faculty of Geography/Geosciences, University of Trier, D-54286 Trier, Germany \\ ${ }^{2}$ Alfred Wegener Institute for Polar and Marine Research, D-14473 Potsdam, Germany
}

\begin{abstract}
In this study we investigate the relationship of the atmospheric circulation and the sea-ice distribution in the Laptev Sea, Arctic Ocean, in the summers 1979-96. Seaice data from passive-microwave radiometers, global atmospheric data analyses, cyclone statistics and simulations of the regional climate model HIRHAM4 were analyzed to find out if periods of reduced or increased sea-ice concentrations are linked to synoptic patterns (circulation anomalies, cyclone activity). A canonical correlation analysis between Arctic sea-level pressure and sea-ice concentration anomalies confirms large-scale relationships among these variables. We did not find a simple relationship between sea-ice area anomalies and cyclone activity in the Laptev Sea area.
\end{abstract}

\section{INTRODUCTION}

Sea ice modifies the exchange of mass, energy and momentum in the planetary boundary layer, and therefore the local and regional climate as well as the general circulation of the atmosphere and the thermohaline oceanic circulation are influenced by sea-ice changes via complex feedbacks in the atmosphere--ocean--sea-ice system.

The seasonal variability of the sea-ice extent in the Arctic ranges from $15 \times 10^{6} \mathrm{~km}^{2}$ in March to $7.6 \times 10^{6} \mathrm{~km}^{2}$ in September, showing extensive temporal and spatial variability. Data analyses show large inter- and intra-annual variabilities of the sea-ice extent (Parkinson and others, 1999). Based on consistent sea-ice concentration (SIC) time series (1979-96) from the Scanning Multichannel Microwave Radiometer (SMMR) and Special Sensor Microwave/Imager (SSM/I) passivemicrowave radiometers, a continuous decrease of Arctic seaice cover of $2.9 \% \pm 0.4 \%$ per decade can be found (Cavalieri and others, 1997). The negative trend is largest during summer. It has strengthened since 1990 and is most pronounced in the East Siberian and Laptev Seas (Serreze and others, 1995; Maslanik and others, 1996). A linear least-squares regression for May-August 1979-96 for the Laptev Sea ice area yields a negative trend of $66184 \mathrm{~km}^{2}$, i.e. a sea-ice area reduction of $36768 \mathrm{~km}^{2}$ per decade (5.5\% per decade) (Fig. 1).

Walsh and Johnson (1979) and Slonosky and others (1997) find significant correlations between sea ice and the atmospheric circulation, based on data with a relatively coarse spatial and temporal resolution. In a simulation with a coupled ice-ocean model, Proshutinsky and Johnson (1997) show, in agreement with observational data, that the Arctic Ocean's circulation regime and sea-ice drift are primarily driven by the near-surface wind fields. Sea-ice anomalies in relatively small areas on time-scales of several days to weeks seem to be strongly coupled with cyclones (Maslanik and Barry, 1989; Maslanik and others, 1996). The results of a high-resolution coupled regional climate model over the Arctic highlight the importance of regional atmospheric circulations in driving interannual variations in Arctic ice extent (Maslanik and others, 2000). The focus in our paper is on the Laptev Sea ice variations and their relation to the atmospheric circulation.

\section{DATASETS}

Four different datasets have been used in the study (see Table 1 for the dataset descriptions and Figure 2 for the locations of the data):

1. The sea-ice concentration data come from satellite observations of the SMMR and SSM/I passive microwave radiometers. They are derived from the brightness temperatures using the NASA-team algorithm with global tie points. Gaps in the SMMR data record (1 January 1979 to 20 August 1987) of every second day were closed

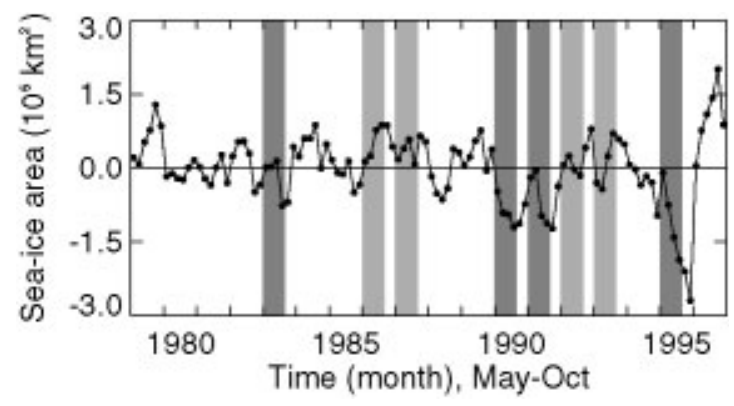

Fig. 1. Time series of monthly anomalies for the Laptev Sea seaice area derived from SMMR and SSM/Idata, May-October 1979-96. See Figure 2 for reference area. Note the breaks in the time series from October to May. The data for this plot were obtained by taking the monthly value for the individual month and subtracting the average value for that month over the 18 year period. The vertical bars mark the months May-August which were simulated with HIRHAM4; light/dark grey: positive/ negative sea-ice anomalies in the Laptev Sea. 
Table 1. Datasets used in this study

\begin{tabular}{|c|c|c|c|c|}
\hline \multirow[t]{2}{*}{ Dataset } & \multicolumn{2}{|c|}{ Resolution } & \multirow[t]{2}{*}{ Period of record } & \multirow[t]{2}{*}{ Source } \\
\hline & Spatial & Temporal & & \\
\hline 1. Sea-ice concentrations & $25 \mathrm{~km} \times 25 \mathrm{~km}$ & Daily averages & 1979-96 & NSIDC \\
\hline 2. SLP & $2.5^{\circ} \times 2.5^{\circ}$ & Daily averages & 1979-96 & NCEP/NCAR re-analysis via NOAA CDC* \\
\hline 3. Cyclone statistics & $250 \mathrm{~km} \times 250 \mathrm{~km}$ & 12 hourly & 1979-93 & $\begin{array}{c}\text { Arctic Cyclone Track Data Set from NSIDC } \\
\text { (Serreze, 1995) }\end{array}$ \\
\hline 4. SLP, $10 \mathrm{~m}$ wind & $50 \mathrm{~km} \times 50 \mathrm{~km}$ & 6 hourly & $\begin{array}{l}\text { MJJA }^{\dagger}: 1983,1986,1987 \\
1990,1991,1992,1993,1995\end{array}$ & HIRHAM4 simulations \\
\hline
\end{tabular}

* Cooperative Institute for Research in Environmental Sciences Climate Diagnostics Center.

$\dagger$ May, June, July, August.

by a linear interpolation between successive time-steps. The spatial coverage is reduced in relation to the original data as indicated in Figure 2. The sea-ice area anomaly time series is calculated without grid elements bordering on land pixels to exclude false sea-ice concentrations due to land-ocean spillover.

2. The daily mean sea-level pressures (SLPs) north of $50^{\circ} \mathrm{N}$ were obtained from the U.S. National Centers for Environmental Prediction/U.S. National Center for Atmospheric Research (NCEP/NCAR) re-analysis project (Kalnay and others, 1996).

3. Cyclone frequencies and intensities for the Laptev Sea area $\left(70-85^{\circ} \mathrm{N}, 70-160^{\circ} \mathrm{E}\right)$ were extracted from the Arctic Cyclone Track Data Set, 1966-93, available from the U.S. National Snow and Ice Data Center (NSIDC) (Serreze, 1995).

4. The mesoscale atmospheric data were obtained through simulations of the regional climate model HIRHAM4, which is applied over the whole Arctic (Fig. 2, "HIRHAM4 model domain") with a horizontal resolution of $0.5^{\circ}$ in latitude and longitude corresponding to grid elements of about $50 \mathrm{~km} \times 50 \mathrm{~km}$ and 19 vertical levels from ground up to $10 \mathrm{hPa}$. Simulations were performed in the summers (May-August) of four years (1983, 1990, 1991,

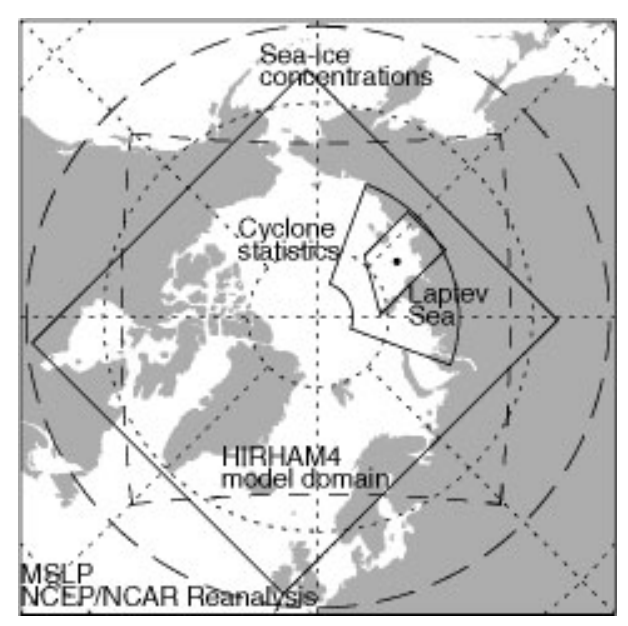

Fig. 2. Spatial distribution of the datasets. The dot symbol marks the reference point at approximately $76.4^{\circ} \mathcal{N}, 125.8^{\circ} \mathrm{E}$, used for the Laptev Sea time series. Dashed line at $50^{\circ} \mathcal{N}$ : NCEP/NCAR re-analysis data; dashed box: HIRHAM4 model domain; solid box: NSIDC sea-ice concentrations; solid semicircle: reference area for cyclone statistics.
1995) with negative sea-ice anomalies and four years (1986, 1987, 1992, 1993) with positive sea-ice anomalies in the Laptev Sea. Several studies, such as Dethloff and others (1996) and Rinke and others (1999), show the performance of this atmospheric model over the Arctic which uses European Centre for Medium-range Weather Forecasts (ECMWF) analysis for the lower and lateral boundary forcing. The sea-surface temperature (SST) at the lower boundary is updated daily by ECMWF analysis. Sea ice covers an entire gridbox with a $2 \mathrm{~m}$ thickness when the SST is below $-1.8^{\circ} \mathrm{C}$. For the present study, time series of SLP and $10 \mathrm{~m}$ wind speed for two years with negative and positive sea-ice area anomalies were extracted at a reference point $\left(76.4^{\circ} \mathrm{N}, 125.8^{\circ} \mathrm{E}\right)$ in the Laptev Sea (Fig. 2).

\section{RELATIONSHIP BETWEEN LARGE-SGALE GIRGU- LATION AND SEA-ICE CONGENTRATIONS}

First, an empirical orthogonal function (EOF) analysis was applied to datasets 1 and 2, i.e. the anomalies of monthly mean SIC and SLPs, to extract the dominant spatial patterns and their temporal variability and strength. The relationship between these two datasets is examined with a canonical correlation analysis (CCA) based on the Barnett and Preisendorfer (1987) method. Input data for the CGA are the calculated EOFs whereby 8 SIC and 11 SLP EOFs were taken into account. The CGA finds a set of mutually uncorrelated canonical correlation patterns (CCPs) whose coefficients share a maximum correlation and indicate the temporal evolution and strength of the pattern.

Table 2 summarizes the results of the CCA. The first correlated mode of variation (the estimated canonical correlation is 0.84 ) represents about $53 \%$ and $40 \%$ of the total variability of the monthly mean SIC and SLP, respectively.

Table 2. Summary of the CCA between 11 SLP and 8 SIC dominant spatial patterns

\begin{tabular}{|c|c|c|c|}
\hline \multirow{3}{*}{$\begin{array}{c}\text { CCP pair } \\
\mathcal{N}_{0} .\end{array}$} & \multirow{3}{*}{$\begin{array}{l}\text { Canonical corre- } \\
\text { lation coefficient }\end{array}$} & \multicolumn{2}{|c|}{ Explained global variance by $C C P$} \\
\hline & & $S L P$ & $S I C$ \\
\hline & & $\%$ & $\%$ \\
\hline 1 & 0.84 & 39.04 & 52.50 \\
\hline 2 & 0.70 & 2.82 & 11.59 \\
\hline 3 & 0.34 & 15.25 & 2.05 \\
\hline 4 & 0.31 & 13.57 & 2.37 \\
\hline
\end{tabular}


a

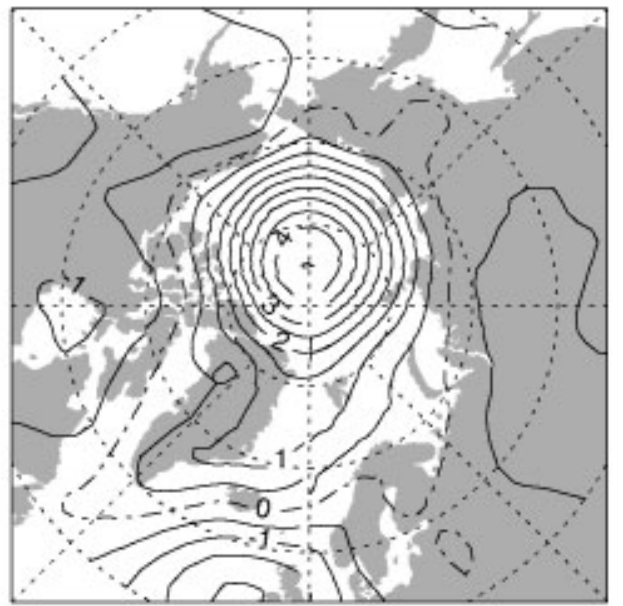

b

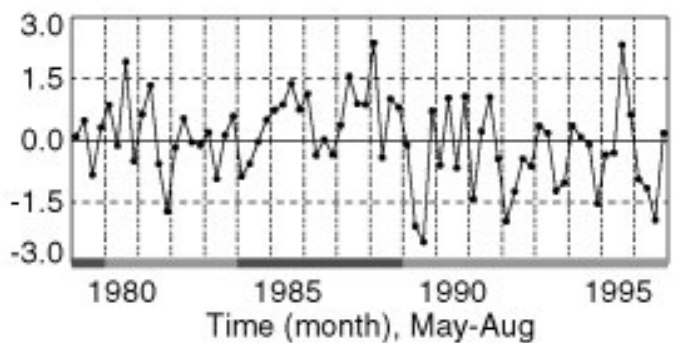

c

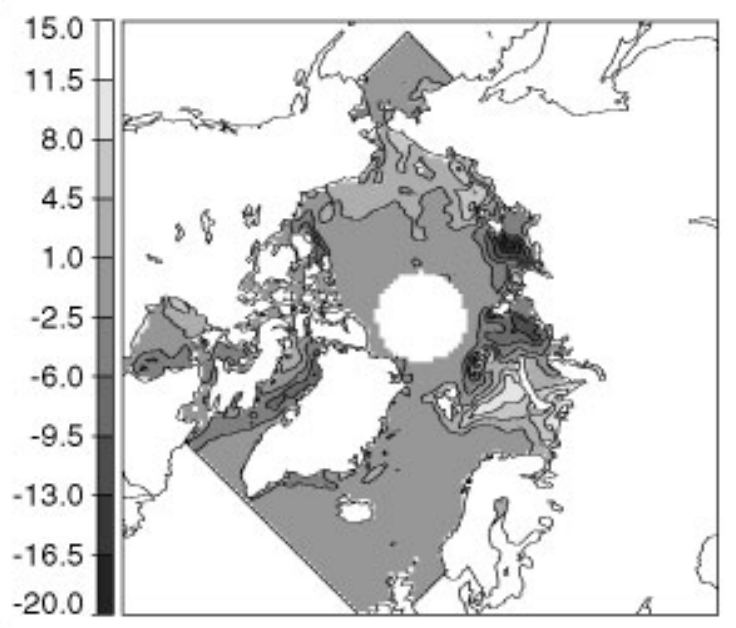

d

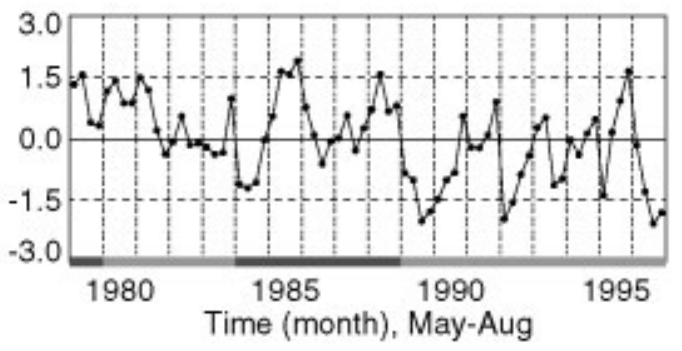

Fig. 3. Third pair of CCPs of (a) sea-level pressure EOFs $(h P a)$ and (c) sea-ice concentration EOFs (\%). (b, d) Time series of the corresponding canonical correlation coefficients, normalized to variance 1. Light/dark grey horizontal bars mark anticyclonic/cyclonic circulation regimes (Polyakov and others, 1999). Note the breaks in the time series from August to May. Base data: datasets 1 and 2.

The pattern of the SLP shows the polar vortex and the mass see-saw between the central Arctic and mid-latitudes, the socalled Arctic Oscillation (Thompson and Wallace, 1998). The pattern of the SIC shows the seasonal decrease of SIC in the Arctic's marginal seas, while the second correlated mode (the estimated canonical correlation is 0.7) shows a rather rare atmospheric circulation pattern (a small global variance of

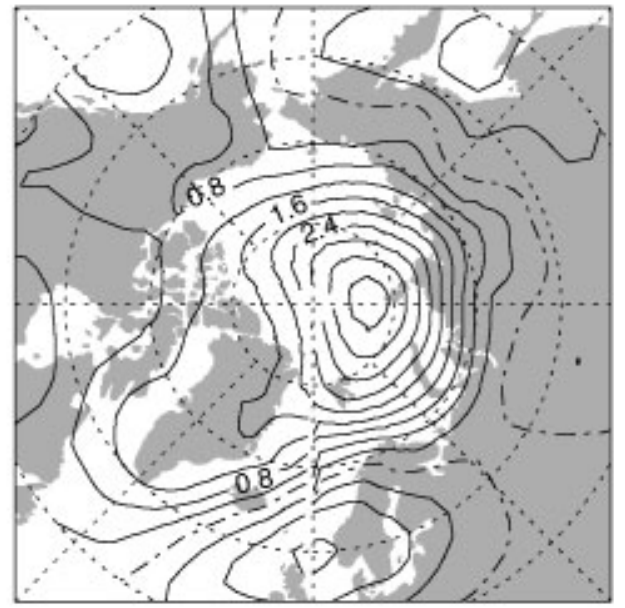

b

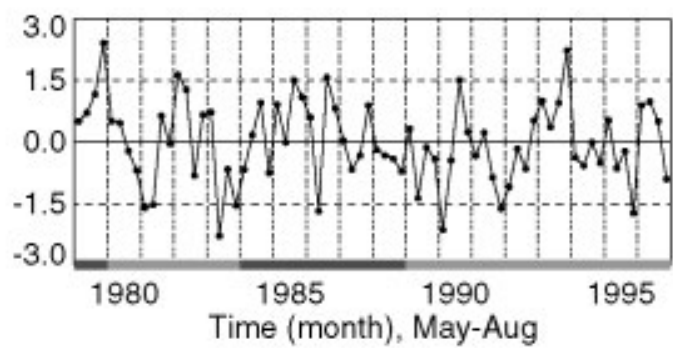

c

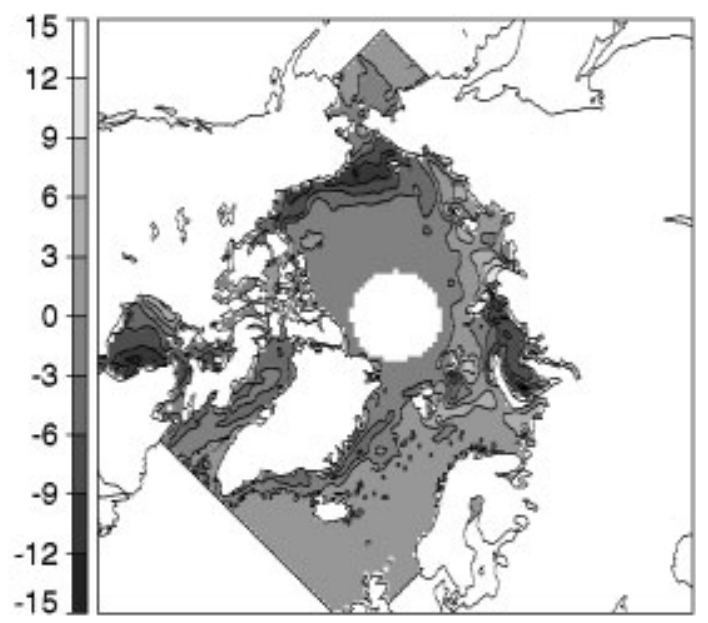

d

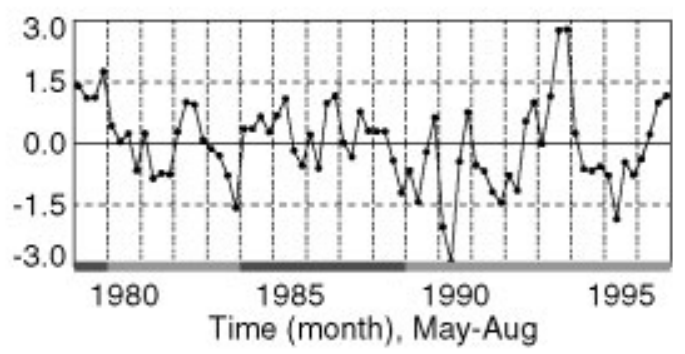

Fig. 4. As in Figure 3 but relative to the fourth pair of CCPS and corresponding canonical correlation coefficients.

only about $3 \%$ ). The latter suggests that cyclone activity can be a driving mechanism of the SIC anomalies (not shown).

The CCP pairs 3 and 4 seem to be important to explain the sea-ice anomalies in the Laptev Sea (the estimated canonical correlation is about 0.3 in each case). In CCP 3, an atmospheric pattern with $15.3 \%$ of explained global variance is coupled with a rather rare sea-ice pattern (Fig. 3). Parts of the northern and central Laptev Sea, the eastern Kara and Barents Seas account for the SIC global variance of only $2.1 \%$, but local variances in these areas (not shown) are as high as $30 \%$. A positive coefficient of the SLP pattern which 
corresponds to an anticyclonic circulation regime prevails especially in the period 1984-88. The SIC decreases at the same time. This is in accordance with the findings of, for example, Proshutinsky and Johnson (1997) that during these regimes the Transpolar Drift Stream shifts towards the Eurasian Shelf seas, which might enhance sea-ice export out of the Siberian marginal seas.

Similar conditions are evident in CGP pair 4 (Fig. 4). Up to $10 \%$ of the local variance is explained by the SIC pattern east of the Taymyr peninsula, in areas which are part of the Taymyr ice massif. In 1983, 1990 and 1995, years with strong negative SIC anomalies in the Laptev Sea, the canonical coefficients are negative, meaning a SIC decrease in these areas. The cyclonic circulation in the northern parts can lead to an increased ice import, but, on the other hand, should increase zonal transport north of $75^{\circ} \mathrm{N}$ and enhance warm-air advection. The coefficient of the SIC pattern remains positive most of the time during the anticyclonic regime in 1979 and 1984-88.

Summarizing, there is evidence that positive and negative sea-ice anomalies may originate from modifications of the sea-ice cover, especially in the central and northern parts of the Laptev Sea and the Taymyr ice massif. They are linked to atmospheric circulation patterns in the central Arctic as shown by CCPs 3 and 4. These findings are similar to those of Deser and others (2000), who conclude that summer sea-ice variations appear to be initiated by atmospheric anomalies over the high Arctic in late spring.

\section{INFLUENGE OF SYNOPTIC AGTIVITY ON SEA-IGE CONGENTRATION}

In order to investigate the relationship between the sea-ice variations and the synoptic activity, we have chosen a twofold approach: First, the frequency and intensity of polar cyclones over the Laptev Sea (dataset 3 ) is compared with the anomalies of the total Laptev Sea sea-ice concentrations. Secondly, time series of local meteorological variables in the planetary boundary layer from the HIRHAM4 model simulations (dataset 4) are compared to the sea-ice concentrations at approximately the same positions in the datasets.

From May to August 1979-93 a total number of 1590 closed low-pressure systems is registered in the Laptev Sea area, $15.4 \%$ of which were cyclogenesis and $13.7 \%$ cyclolysis events. The average is 26.5 systems per month. The number of systems increases by 2.27 per season (May-August), while the mean central pressure decreases slightly. An increased cyclone activity can enhance warm-air advection and lead to a larger shear stress and sea-ice drift. Baroclinic instabilities can arise which in turn lead to an increased ice divergence (Tansley and James, 1999). This is what happened in May 1990, when a strong low-pressure system was located northwest of the Laptev Sea (Serreze and others, 1995).

We correlated sea-ice area anomalies and cyclone activity (numbers of low-pressure systems, mean central pressure as cyclone intensity, numbers of cyclones with pressure below $990 \mathrm{hPa}$ ) in the Laptev Sea, but a simple relationship between these parameters does not exist (Fig. 5). Both positive and negative ice anomaly years - independent of the atmospheric circulation regime - show a large cyclone activity (e.g. 1986, 1990).

In the next step we correlated Laptev Sea SIC data with meteorological parameters extracted from the high-resolution atmospheric model simulations. The time series for 1986 and a

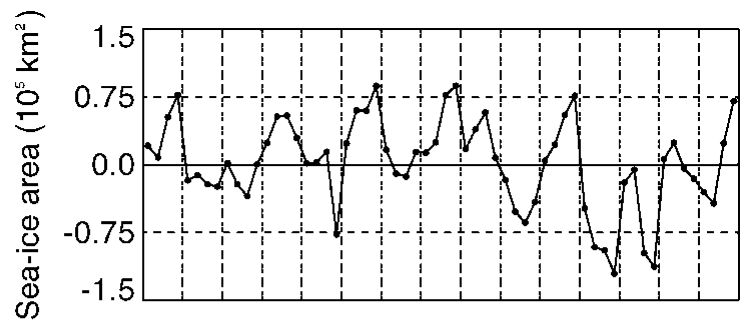

b

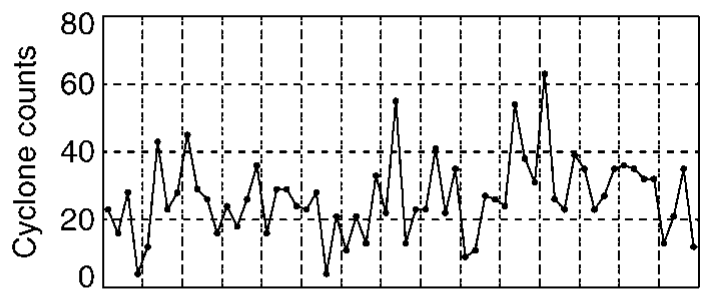

C

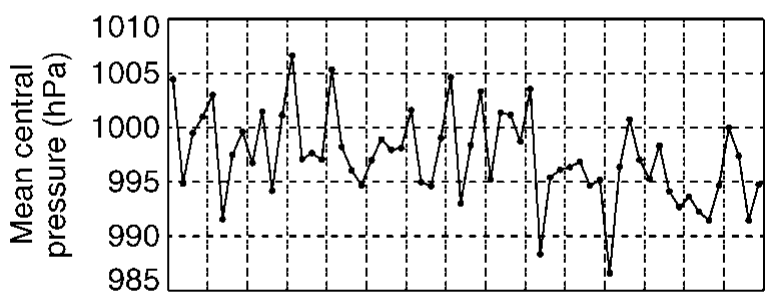

d

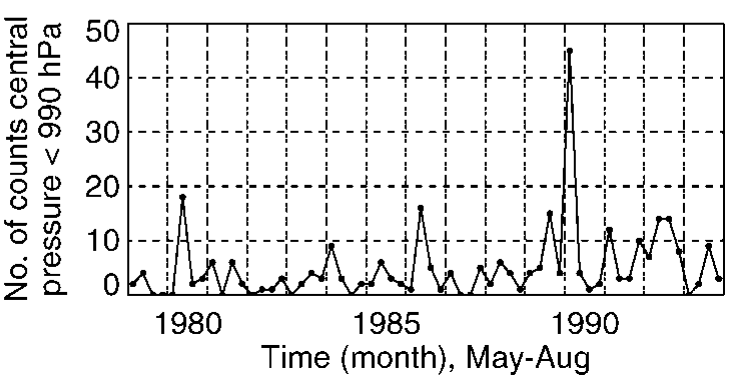

Fig. 5. Time series, May-August 1979-93, of monthly means of (a) Laptev Sea ice area anomalies, (b) cyclone counts at $70-85^{\circ} \mathcal{N}, 70-160^{\circ} \mathrm{E},(\mathrm{c})$ mean central pressure of these systems, and $(d)$ the number of systems with a central pressure of $<990 \mathrm{hPa}$.

1990, plotted in Figure 6, are examples of years with positive and negative sea-ice anomalies in the central Laptev Sea at approximately $76.4^{\circ} \mathrm{N}, 125.8^{\circ} \mathrm{E}$.

From May to July 1986, the SIC at the reference point remains above $80 \%$ with few exceptions. The measured SIC reduction around 5 June is probably caused by melt ponding. With no free drift conditions the cyclone activity in June is unlikely to have an immediate effect on the SIC. The SIC decrease at 8 August is accompanied by a pressure decrease to about $998 \mathrm{hPa}$ and wind speeds of about $20 \mathrm{~m} \mathrm{~s}^{-1}$. After the slightly enhanced synoptic activity in mid-July and an increase in the system's intensity (second spatial derivation, not shown), the SIC starts to drop by around $40 \%$ during the last 3 days in August and reaches open-water conditions 9 days later in early September.

During May 1990 the SIC is constantly above 90\%. Cyclone activity is as high as 35 systems per month, with central pressures at a minimum of $976 \mathrm{hPa}$. Each time wind speed exceeds $20 \mathrm{~ms}^{-1}$, there follows a slight decrease in SIC. The reduced SIC in the first half of June is probably caused by melt ponding and a substantial meltwater buildup within and at the base of the snow cover (Bareiss and others 1999). Cyclone activity decreases to 12 systems, and 
a

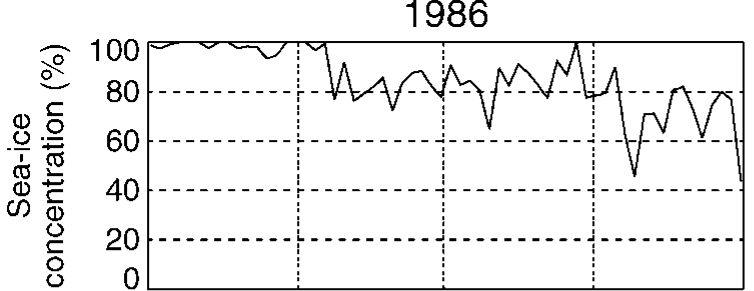

b
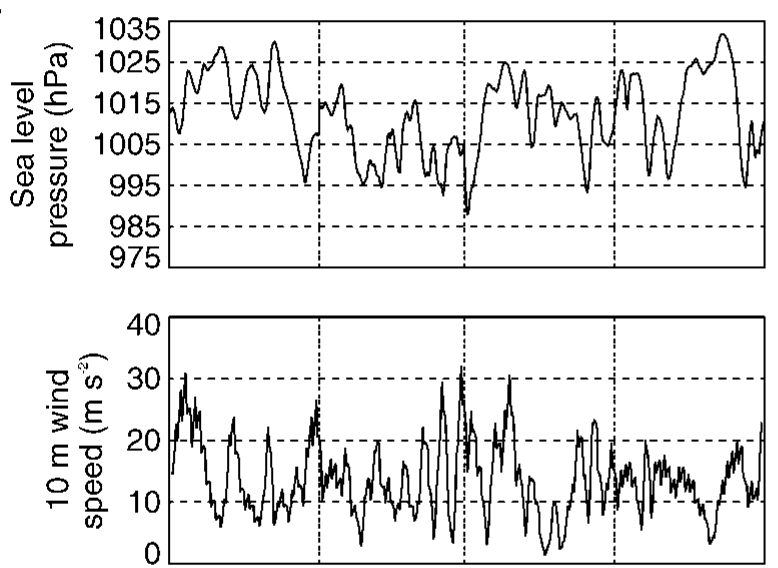

d

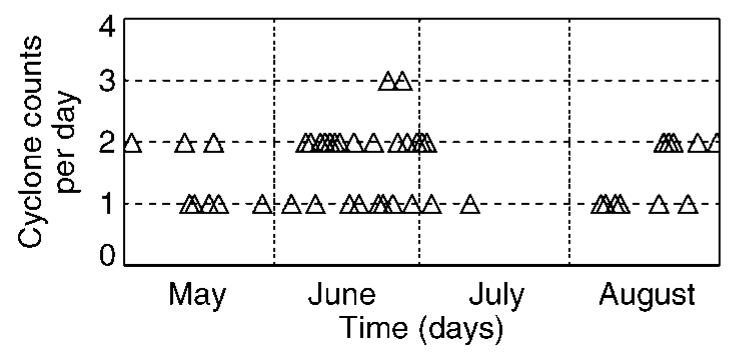

1990


Fig. 6. Time series of (a) sea-ice concentrations ( NSIDC), (b) sea-level pressure and (c) $10 \mathrm{~m}$ wind speed (HIRHAM4) at approximately $76.4^{\circ} \mathcal{N}, 125.8^{\circ}$ E, and (d) cyclone counts (Arctic Cyclone Track Data Set) at 70-82 $\mathcal{N}, 90-145^{\circ}$ E, for summers with positive (1986) and negative (1990) sea-ice area anomalies in the Laptev Sea. The temporal resolution of SLP is 6 hours. The $10 \mathrm{~m}$ wind-speed components are averaged over 6 hours and low-pass filtered (with a filter width of 5 elements). The SIC and the number of all registered, closed cyclones between $70-82^{\circ} \mathcal{N}$ and $90-145^{\circ}$ E have a temporal resolution of 1 day.

wind speed drops to a minimum of $1.6 \mathrm{~m} \mathrm{~s}^{-1}$. In the second half of June, SIC starts to decrease continuously until open water is reached, with a sharp decrease at the end of the month of approximately $10 \%$ SIC in 24 hours. This is not accompanied by anomalously intense atmospheric conditions. The spatial distribution of the SIC data shows that the West New Siberian polynya extends to this position. A distinction between dynamic and thermodynamic components is currently not possible.

The data suggest that atmospheric processes, especially Arctic cyclones, may predispose the ice cover by enhancing the shear stress on the sea ice, which facilitates ablation and drifting at a later stage. Maslanik and others (2000) showed in a coupled model experiment for 1990 the importance of regional atmospheric circulation placement and strength of high- and low-pressure systems in driving patterns and velocity of sea-ice transport.

\section{SUMMARY}

The influence of the atmospheric circulation on the SIC at different spatial and temporal resolutions has been investigated for May-August 1979-96 for the Laptev Sea. The major conclusions are the following:

1. The CCA shows SIC patterns statistically significantly correlated to large-scale SLP fields. The SIC anomalies in the Laptev Sea depend on relatively rare atmospheric circulation patterns which might be attributed to cyclone activity. Negative SIC anomalies in the central, northern and northwestern parts (Taymyr ice massif) seem to depend on ice drift caused either by a shift of the largescale ocean currents or by wind-driven ice export, when cyclonic circulation dominates the northern Laptev Sea.

2. Short-term SIC variations seem to be connected to synoptic-scale low-pressure systems, but no simple relationship can be found between the SIC decrease and cyclone activity.

A complex time-dependent combination of dynamic and thermodynamic processes, including sea-ice properties such as ice thickness and sea-ice drift to and from adjacent areas, must be taken into account. Further diagnostic studies of single events incorporating drift data and experiments with a coupled regional-scale model as started by Maslanik and others (2000) are necessary.

\section{ACKNOWLEDGEMENTS}

We would like to thank: EOSDIS NSIDG Distributed Data Archive Center, University of Boulder, Colorado, for providing 
the SIC data record and the Arctic Cyclone Track Data Set; NCEP/NGAR for re-analysis data via U.S. National Oceanic and Atmospheric Administration Climate Diagnostics Center; Deutsches Klimarechenzentrum and Max Planck Institute for Meteorology, Hamburg, for providing computational resources and software. The comments of two anonymous reviewers aided in the preparation of this paper.

\section{REFERENCES}

Bareiss, J., H. Eicken, A. Helbig and T. Martin. 1999. Impact of river discharge and regional climatology on the decay of sea ice in the Laptev Sea during spring and early summer. Arct. Antarct. Alp. Res., 31 (3), 214-229.

Barnett, T.B. and R. Preisendorfer. 1987. Origins and levels of monthly and seasonal forecast skill for United States surface air temperatures determined by canonical correlation analysis. Mon. Weather Rev., 115 (9), 1825-1850.

Cavalieri, D. J., P. Gloersen, C. L. Parkinson, J. C. Comiso and H. J. Zwally. 1997. Observed hemispheric asymmetry in global sea ice changes. Science, 278(5340), 1104-1106.

Deser, C., J. E. Walsh and M. S. Timlin. 2000. Arctic sea ice variability in the context of recent atmospheric circulation trends. F. Climate, 13(3), 617-633.

Dethloff, K., A. Rinke, R. Lehmann, J. H. Christensen, M. Botzet and B. Machenhauer. 1996. A regional climate model of the Arctic atmosphere. 7. Geophys. Res., 101 (D18), 23,401-23,422.

Kalnay, E. and 21 others. 1996. The NCEP/NCAR 40-year reanalysis project. Bull. Am. Meteorol. Soc., 77(3), 437-471.

Maslanik, J. A. and R. G. Barry. 1989. Short-term interactions between atmospheric synoptic conditions and sea-ice behaviour in the Arctic. Ann. Glaciol., 12, 113-117.
Maslanik, J. A., M. C. Serreze and R. G. Barry. 1996. Recent decreases in Arctic summer ice cover and linkages to atmospheric circulation anomalies. Geophys. Res. Lett., 23 (13), 1677-1680.

Maslanik, J. A., A. H. Lynch, M. C. Serreze and W. Wu. 2000. A case study of regional climate anomalies in the Arctic: performance requirements for a coupled model. f. Climate, 13(2), 383-401.

Parkinson, C. L., D. J. Cavalieri, P. Gloersen, H. J. Zwally and J. C. Comiso. 1999. Arctic sea ice extents, areas, and trends, 1978-1996. F. Geophys. Res., 104 (C9), 20,837-20,856.

Polyakov, I. V., A.Yu. Proshutinsky and M. A. Johnson. 1999. The seasonal cycles in two regimes of Arctic climate. 7. Geophys. Res., 104(Cl1), 25,761-25,788.

Proshutinsky, A.Yu. and M. A. Johnson. 1997. Two circulation regimes of the wind-driven Arctic Ocean. F. Geophys. Res., 102(C6), 12,493-12,514.

Rinke, A., K. Dethloff, A. Spekat, W. Enke and J. H. Christensen. 1999. High resolution climate simulations over the Arctic. Polar Res., 18(2), 1-9.

Serreze, M. C. 1995. Climatological aspects of cyclone development and decay in the Arctic. Atmosphere-Ocean, 33(1), 1-23.

Serreze, M. C., J. A. Maslanik, J. R. Key, R. F. Kokaly and D. A. Robinson. 1995. Diagnosis of the record minimum in Arctic sea ice during 1990 and associated snow cover extremes. Geophys. Res. Lett., 22(16), 2183-2186.

Slonosky, C. S., L. A. Mysak and J. Derome. 1997. Linking Arctic sea-ice and atmospheric circulation anomalies on interannual and decadal timescales. Atmosphere-Ocean, 35(3), 333-336.

Tansley, C. E. and I. N. James. 1999. Feedbacks between sea ice and baroclinic waves using a linear quasi-geostrophic model. Q. 7. R. Meteorol. Soc., $\mathbf{1 2 5}(559), 2517-2534$

Thompson, D.W. J. and J.W. Wallace. 1998. The Arctic Oscillation signature in the wintertime geopotential height and temperature fields. Geophys. Res. Lett., 25(9), 1297-1300.

Walsh, J. E. and C. M. Johnson. 1979. An analysis of Arctic sea ice fluctuations, 1953-1977. 7. Phys. Oceanogr., 9(3), 580-591. 